\title{
Hubungan Kesiapan Keluarga Menerima Klien Dengan Gangguan Jiwa Terhadap Angka Kekambuhan Pada Klien Gangguan Jiwa Di Poliklinik Rumah Sakit Jiwa Sambang Lihum Tahun 2018
}

\author{
Muhammad Saputra \\ Sekolah Tinggi Ilmu Kesehatan Cahaya Bangsa Banjarmasin \\ Putra.muhammad07@gmail.com
}

DOI: https://doi.org/10.33859/dksm.v10i2.506

Abstrak
Latar belakang: Gangguan jiwa merupakan salah satu masalah kesehatan masyarakat di Indonesia.
Klien gangguan jiwa dicirikan dengan siklus kekambuhan yang mencapai 60-75\% dari keseluruhan
penderita. Kekambuhan klien masih tinggi dapat dipengaruhi faktor kesiapan keluarga dalam
menerima klien gangguan jiwa.
Tujuan: Penelitian ini bertujuan untuk mengetahui hubungan kesiapan keluarga menerima klien
dengan gangguan jiwa terhadap angka kekambuhan pada klien gangguan jiwa di Poliklinik Rumah
Sakit Jiwa Sambang Lihum
Metode: analitik dengan rancangan cross sectional. Populasi adalah seluruh keluarga (keluarga inti)
klien gangguan jiwa di Poliklinik Rumah Sakit Jiwa Sambang Lihum yang berjumlah 1.751 orang.
Sampel sebagian dari populasi sebanyak 97 orang dengan teknik pengambilan puposive sampling.
Analisis data melalui uji Spearman Rank dengan tingkat kepercayaan 95\%.
Hasil: Didapatkan keluarga klien gangguan jiwa sebagian besar siap dalam menerima klien gangguan
jiwa sebanyak 77 orang (79,4\%) dan angka kekambuhan klien gangguan jiwa sebagian besar kategori
sedang sebanyak 65 orang (67\%). Ada hubungan kesiapan keluarga dalam menerima klien dengan
angka kekambuhan pada klien gangguan jiwa di Poliklinik Rumah Sakit Jiwa Sambang Lihum
Provinsi Kalimantan Selatan (p value = 0,000; $\mathrm{r}=0,744)$.
Simpulan: rumah sakit hendaknya memberikan sosialisasi misalnya melalui kegiatan peningkatan
home visite kepada keluarga pasien untuk meningkatkan kesiapan keluarga untuk menerima klien.
Kata Kunci: Angka Kekambuhan, Kesiapan Menerima Klien.




\section{Abstract}

Background: Mental disorders is one of the problems of public health in Indonesia. The mental impairment client is characterized by a relapse cycle that reaches $60-75 \%$ of the sufferer. Client relapse is still high can be influenced by family readiness factor in receiving the client's mental disorders.

Purpose: PEnelitian aims to know the family readiness relationship to receive clients with a mental impairment on the number of relapses in Mental disorders in the clinic of mental illness in Sambang Lihum

Method: cross sectional analytic. Population is the whole family (core family) of the clients of mental disorders in the polyclinic of the Sambang Lihum psychiatric hospital amounting to 1,751 people. Samples of a portion of the population of 97 people with puposive samplingtechniques. Analysis of data by Test Spearman Rank with a trust rate of $95 \%$.

Results: obtained by the family of mental disorders clients are mostly ready in receiving clients of mental disorders as much as 77 people (79.4\%) and the number of mental impairment clients of most categories is currently 65 people (67\%). There is a family readiness relationship in accepting clients with a number of relapse on the client's mental disorder in the clinic of health care Sambang Lihum South Kalimantan Province ( $P$ value $=0.000 ; r=0.744$ ).

Suggestion: RHospital should provide socialization e.g. through home visite Improvement activities to the patient family to improve the family readiness to receive clients.

Keywords: number of relapses, readiness of accepting clients

\section{Pendahuluan}

Kesehatan jiwa menurut World Health

Organization (WHO) adalah ketika seseorang

tersebut merasa sehat dan bahagia, mampu menghadapi tantangan hidup serta dapat menerima orang lain sebagaimana seharusnya serta mempunyai sikap positif terhadap diri sendiri dan orang lain.

Data stastistik yang dikemukan oleh

\section{World Health Organization (WHO)}

menyebutkan bahwa sekitar 450 juta di dunia

mengalami masalah gangguan kesehatan

jiwa.Sepertiga di antaranya terjadi di negara berkembang, sedangkan di Kalimantan Selata jumlah penyandang gangguan jiwa diperkirakan mencapai 6.000 orang. Jumlah tersebut harus terus di antisipasi oleh seluruh pihak terkait, sehingga pengobatan bisa dilakukan dengan maksimal.

Kesadaran keluarga dan masyarakat untuk membawa anggota keluarganya yang mengalami gangguan jiwa sangat minim, karena berbagai faktor antara lain karena malu. Selama ini sebagian besar pasien yang keluar dari rumah sakit enggan untuk mengikuti perawatan lanjutan, karena berbagai faktor 
Dinamika Kesehatan Jurnal Kebidanan dan Keperawatan Vol 10 No. 22019 ( ISSN: 2086-3454 EISSN: 2549-4058)

url: http://ojs.dinamikakesehatan.unism.ac.id DOI: https://doi.org/10.33859/dksm.v10i2

Hubungan Kesiapan Keluarga Menerima Klien Dengan Gangguan Jiwa Terhadap Angka Kekambuhan Pada Klien Gangguan Jiwa Di Poliklinik Rumah Sakit Jiwa Sambang Lihum Tahun 2018

trauma dan lainnya. Persoalan lain yang kini

juga harus terus disosialsasikan ke keluarga dan masyarakat adalah stigma terhadap penderita gangguan jiwa, yang sulit kembali ke keluarga walaupun sudah sembuh. Keluarga rata-rata sulit untuk menerima mantan penderita gangguan jiwa layaknya anggota keluarga yang normal (http://m.harnas.co).

Keluarga merupakan tempat sosialisai pertama bagi penderita gangguan jiwa yang menjalani rawat inap saat penderita pulang ke rumah sebelum penderita kembali ke masyarakat. Kesiapan keluarga untuk menghadapi kembali penderita gangguan jiwa kembali ke rumah sangat penting. Namun kenyataannya beberapa keluarga pasien menunjukkan ketidaksiapan dalam menghadapi kepulangan pasien kembali ke rumah (Amalia, 2009).

Data di Poliklinik Rumah Sakit Jiwa Sambang Lihum menyatakan jumlah kunjungan klien hingga bulan Juni 2018 seluruhnya sebanyak 1751 orang dengan jenis kelamin laki-laki 1232 orang dan perempuan
519 orang perbulannya dalam sehari rata-rata 58,37 klien.

Hasil studi pendahuluan pada tanggal 22 Mei 2018 dari hasil wawancara kepada keluarga klien sebanyak 12 orang, 7 orang klien yang mengalami kekambuhan $>3$ kali, 4 orang klien mengalami kekambuhan 3 kali dan 1 orang klien mengalami kekambuhan 2 kali. Dari 12 orang keluarga klien sebanyak 8 orang tidak siap dalam menerima klien di rumah sedangkan 3 orang lainnya menyatakan siap dalam menerima klien di rumah, hal ini dibuktikan dengan mereka setiap harinya mengajak klien untuk beribadah bersama-sama di rumah.

\section{Metode}

Metode penelitian yang digunakan adalah analitik dengan rancangan cross sectional. Populasi adalah seluruh keluarga (keluarga inti) klien gangguan jiwa di Poliklinik Rumah Sakit Jiwa Sambang Lihum yang berjumlah 1.751 orang. Sampel sebagian dari populasi sebanyak 97 orang dengan teknik pengambilan purposive sampling. Lokasi penelitian ini dilakukan di Rumah Sakit 
Dinamika Kesehatan Jurnal Kebidanan dan Keperawatan Vol 10 No. 22019 ( ISSN: 2086-3454 EISSN: 2549-4058)

url: http://ojs.dinamikakesehatan.unism.ac.id DOI: https://doi.org/10.33859/dksm.v10i2

Hubungan Kesiapan Keluarga Menerima Klien Dengan Gangguan Jiwa Terhadap Angka Kekambuhan Pada Klien Gangguan Jiwa Di Poliklinik Rumah Sakit Jiwa Sambang Lihum Tahun 2018

Sambang Lihum Jl.Gubernur Syarkawi km 3,9

Gambut Banjarmasin. Penelitian dilakukan

pada bulan Juli - Agutus 2018. Variabel independen adalah kesiapan keluarga menerima klien dengan gangguan jiwa dan variabel adalah angka kekambuhan klien gangguan jiwa. Alat pengumpul data menggunakan kuesioner. Jenis data terdiri dari primer dan sukunder. Data primer meliputi kesiapan keluarga dan angka kekambuhan yang bersumber dari keluarga klien gangguan jiwa. Analisis data melalui uji Spearman Rank dengan tingkat kepercayaan $95 \%$.

\section{Hasil}

Hasil penelitian ini antara lain:

1. Karakteristik responden

a. Umur responden

Karakteristik responden berdasarkan umur dapat dilihat pada tabel 1 .

Tabel 1 Umur Responden di Poliklinik Rumah Sakit Jiwa Sambang Lihum Provinsi Kalimantan Selatan Tahun 2018

\begin{tabular}{|c|c|c|c|}
\hline \multirow{2}{*}{$\begin{array}{l}\text { No } \\
\text {. }\end{array}$} & \multirow{2}{*}{$\begin{array}{l}\text { Umur } \\
\text { (Tahun) }\end{array}$} & \multicolumn{2}{|c|}{ Jumlah } \\
\hline & & $\begin{array}{c}\text { Frekuensi } \\
\text { (orang) }\end{array}$ & $\begin{array}{c}\text { Persentase } \\
(\%)\end{array}$ \\
\hline 1 & $\begin{array}{l}\text { Dewasa } \\
\text { muda ( } \leq 30 \\
\text { tahun) }\end{array}$ & 32 & 33,0 \\
\hline 2 & $\begin{array}{l}\text { Dewasa } \\
\text { setengah } \\
\text { baya (31-60 } \\
\text { tahun) }\end{array}$ & 63 & 64,9 \\
\hline 3 & $\begin{array}{l}\text { Lansia ( }>60 \\
\text { tahun) }\end{array}$ & 2 & 2,1 \\
\hline & Jumlah & 97 & 100 \\
\hline
\end{tabular}

Tabel 1 menunjukkan bahwa umur responden dengan kategori dewasa muda sebanyak 32 orang (33\%), umur responden dengan kategori dewasa setengah baya ( 31 - 60 tahun) sebesar 63 orang $(64,9 \%)$ dan umur respoden dengan kategori lansia sebanyak 2 orang $(2,1 \%)$. Berdasarkan data tersebut responden sebagian besar memiliki umur dengan kategori dewasa setang baya (31-60 tahun).

b. Jenis kelamin responden

Karakteristik responden berdasarkan jenis kelamin dapat dilihat pada tabel 2.

Tabel 2 Jenis Kelamin Responden di Poliklinik Rumah Sakit Jiwa Sambang Lihum Provinsi Kalimantan Selatan Tahun 2018

\begin{tabular}{cccc}
\hline No. & \multirow{2}{*}{$\begin{array}{c}\text { Jenis } \\
\text { Kelamin }\end{array}$} & $\begin{array}{c}\text { Jumlah } \\
\text { (orang) }\end{array}$ & $\begin{array}{c}\text { Persentase } \\
(\%)\end{array}$ \\
\hline 1 & Perempuan & 35 & 36,1 \\
2 & Laki-laki & 62 & 63,9 \\
\hline & Jumlah & 97 & 100 \\
\hline
\end{tabular}

Sumber: Data Primer di RSJ Sambang Lihum

Tabel 2 menunjukkan bahwa responden perempuan sebanyak 35 orang $(36,1 \%)$ sedangkan laki-laki sebanyak 62 orang $(63,9 \%)$. Berdasarkan data tersebut responden sebagian besar memiliki jenis kelamin laki-laki.

c. Status hubungan responden dengan pasien

Karakteristik responden berdasarkan status hubungan dengan pasien dapat dilihat pada tabel 3 .

Tabel 3 Status Hubungan Responden dengan Klien di Poliklinik Rumah Sakit Jiwa Sambang Lihum Provinsi Kalimantan Selatan Tahun 2018

\begin{tabular}{|c|c|c|c|}
\hline \multirow[b]{2}{*}{ No. } & \multirow{2}{*}{$\begin{array}{c}\text { Status } \\
\text { Hubungan }\end{array}$} & \multicolumn{2}{|c|}{ Jumlah } \\
\hline & & $\begin{array}{c}\text { Frekuensi } \\
\text { (orang) }\end{array}$ & $\begin{array}{c}\text { Persentase } \\
(\%)\end{array}$ \\
\hline 1 & Orang tua & 23 & 23,7 \\
\hline 2 & Anak & 34 & 35,1 \\
\hline 3 & Suami/istri & 16 & 16,5 \\
\hline 4 & Suadara & 24 & 24,7 \\
\hline & Jumlah & 97 & 100 \\
\hline
\end{tabular}

Sumber: Data Primer di RSJ Sambang Lihum 
Dinamika Kesehatan Jurnal Kebidanan dan Keperawatan Vol 10 No. 22019 ( ISSN: 2086-3454 EISSN: 2549-4058)

url: http://ojs.dinamikakesehatan.unism.ac.id DOI: https://doi.org/10.33859/dksm.v10i2

Hubungan Kesiapan Keluarga Menerima Klien Dengan Gangguan Jiwa Terhadap Angka Kekambuhan Pada Klien Gangguan Jiwa Di Poliklinik Rumah Sakit Jiwa Sambang Lihum Tahun 2018

Tabel 3 menunjukkan bahwa orang tua klien jiwa sebanyak 23 orang $(23,7 \%)$, anak dari klien jiwa 34 orang $(35,1 \%)$, suami/istri dari klien jiwa sebanyak 16 orang $(16,5 \%)$ dan saudara dari klien jiwa sebanyak 24 orang $(24,7 \%)$. Berdasarkan data tersebut responden sebagian besar adalah anak dari kline jiwa.

\section{Analisa univariat}

a. Kesiapan keluarga dalam menerima klien gangguan jiwa

Kesiapan keluarga dalam menerima klien gangguan jiwa di Poliklinik Rumah Sakit Jiwa Sambang Lihum Provinsi Kalimantan Selatan dapat dilihat pada tabel 4

Tabel 4 Kesiapan Keluarga dalam Menerima Klien Gangguan Jiwa di Poliklinik Rumah Sakit Jiwa Sambang Lihum Provinsi Kalimantan Selatan Tahun 2018

\begin{tabular}{cccc}
\hline \multirow{2}{*}{ No. } & \multirow{2}{*}{$\begin{array}{c}\text { Kesiapan } \\
\text { Keluarga }\end{array}$} & $\begin{array}{c}\text { Jrekuensi } \\
\text { (orang) }\end{array}$ & $\begin{array}{c}\text { Persentase } \\
(\%)\end{array}$ \\
\hline 1 & Siap & 77 & 79,4 \\
\hline 2 & Tidak siap & 20 & 20,6 \\
\hline & Jumlah & 97 & 100 \\
\hline
\end{tabular}

Sumber: Data Primer di RSJ Sambang Lihum

Tabel 4 menunjukkan bahwa keluarga yang siap dalam menerima klien gangguan jiwa sebanyak 77 orang $(79,4 \%)$ dan keluarga yang tidak siap dalam menerima klien gangguan jiwa sebanyak 20 orang $(20,6 \%)$. Berdasarkan data tersebut didapatkan bahwa keluarga klien jiwa sebagian besar siap dalam menerima klien gangguan jiwa.

b. Angka kekambuhan klien gangguan jiwa Angka kekambuhan klien gangguan jiwa di Poliklinik Rumah Sakit Jiwa Sambang Lihum Provinsi Kalimantan Selatan dapat dilihat pada tabel 5 .
Tabel 5 Angka Kekambuhan Klien Gangguan Jiwa di Poliklinik Rumah Sakit Jiwa Sambang Lihum Provinsi Kalimantan Selatan Tahun 2018

\begin{tabular}{cccc}
\hline \multirow{2}{*}{ No } & Angka & \multicolumn{2}{c}{ Jumlah } \\
$\cdot$ & Kekambuha & Frekuens & Persentas \\
& $\mathrm{n}$ & $\mathrm{i}$ (orang) & $\mathrm{e}(\%)$ \\
\hline 1 & Rendah & 5 & 5,2 \\
2 & Sedang & 65 & 67,0 \\
3 & Tinggi & 27 & 27,8 \\
\hline & Jumlah & 97 & 100 \\
\hline
\end{tabular}

Sumber: Data Primer di RSJ Sambang Lihum

Tabel 5 menunjukkan angka kekambuhan klien gangguan jiwa dengan kategori rendah sebanyak 5 orang $(5,2 \%)$, sedang sebanyak 65 orang (67\%) sedangkan angka kekambuhan klien gangguan jiwa dengan kategori tinggi sebanyak 27 oarng $(27,8 \%)$.

3. Analisis bivariat

Hasil analisis hubungan kesiapan keluarga dalam menerima klien dengan angka kekambuhan klien gangguan jiwa di Rumah Sakit Jiwa Sambang Lihum Provinsi Kalimantan Selatan dapat dilihat pada tabel 6.

Tabel 6 Hubungan Kesiapan Keluarga dengan Angka Kekambuhan Klien Gangguan Jiwa di Poliklinik Rumah Sakit Jiwa Sambang Lihum Provinsi Kalimantan Selatan Tahun 2018

\begin{tabular}{|c|c|c|c|c|c|c|c|c|c|}
\hline \multirow{3}{*}{ No } & \multirow{3}{*}{$\begin{array}{l}\text { Kesiapan } \\
\text { Keluarga }\end{array}$} & \multicolumn{6}{|c|}{ Angka Kekambuhan } & \multicolumn{2}{|c|}{ Jumlah } \\
\hline & & \multicolumn{2}{|c|}{ Rendah } & \multicolumn{2}{|c|}{ Sedang } & \multicolumn{2}{|c|}{ Tinggi } & \multirow{2}{*}{ f } & \multirow{2}{*}{$\%$} \\
\hline & & $\mathrm{f}$ & $\%$ & $\mathrm{f}$ & $\%$ & $\mathrm{f}$ & $\%$ & & \\
\hline 1 & Siap & 5 & 6,5 & 65 & 84,4 & 7 & 9,1 & 77 & 100 \\
\hline \multirow[t]{3}{*}{2} & $\begin{array}{l}\text { Tidak } \\
\text { siap }\end{array}$ & 0 & 0 & 0 & 0 & 20 & 100 & 20 & 100 \\
\hline & Jumlah & 5 & 5,2 & 65 & 67 & 27 & 27,8 & 97 & 100 \\
\hline & \multicolumn{9}{|c|}{ Hasil uji Spearman Rank nilai $\mathrm{p}=0,000, \mathrm{r}=0,774$} \\
\hline
\end{tabular}

Tabel 6 menunjukkan bahwa dari 77 orang

keluarga yang siap menerima klien sebagian besar klien gangguan jiwa mengalami angka kekambuhan dengan kategori sedang sebanyak 65 orang $(84,4 \%)$ sedangkan dari 20 orang keluarga yang 
Dinamika Kesehatan Jurnal Kebidanan dan Keperawatan Vol 10 No. 22019 ( ISSN: 2086-3454 EISSN: 2549-4058)

url: http://ojs.dinamikakesehatan.unism.ac.id DOI: https://doi.org/10.33859/dksm.v10i2

Hubungan Kesiapan Keluarga Menerima Klien Dengan Gangguan Jiwa Terhadap Angka Kekambuhan Pada Klien Gangguan Jiwa Di Poliklinik Rumah Sakit Jiwa Sambang Lihum Tahun 2018

tidak siap dalam menerima klien seluruh

klien gangguan jiwa mengalami angka kekambuhan dengan kategori tinggi sebanyak $100 \%$.

Hasil analisis dengan menggunakan uji statistik Spearman Rank didapatkan nilai $\mathrm{p}$ sebesar 0,000. Nilai tersebut secara statistik lebih kecil dari nilai $\alpha(0,05)$. Hal ini menunjukkan bahwa ada hubungan kesiapan keluarga dalam menerima klien dengan angka kekambuhan pada klien gangguan jiwa di Poliklinik Rumah Sakit Jiwa Sambang Lihum Provinsi Kalimantan Selatan.

Nilai korelasi Spearman Rank sebesar 0,774 menunjukkan bahwa kekuatan korelasi yang sangat kuat, dapat diartikan bahwa semakin siap keluarga dalam menerima klien maka akan semakin rendah angka kekambuhan klien gangguan jiwa.

\section{Pembahasan}

1. Kesiapan keluarga dalam menerima klien gangguan jiwa di Poliklinik Rumah Sakit Jiwa Sambang Lihum Provinsi Kalimantan Selatan
Hasil penelitian didapatkan bahwa keluarga sebagian besar siap dalam merawat pasien gangguan jiwa yaitu sebanyak 77 orang $(79,4 \%)$. Data tersebut menunjukkan bahwa keluarga banyak yang sudah sedia untuk memberikan perawatan kepada pasien gangguan jiwa, namun data lainnya menunjukkan masih adanya keluarga yang belum siap sedia untuk menerima, merawat, mengontrol dan meningkatkan status kesehatan pasien gangguan jiwa agar penyakit pasien tidak kambuh kembali.

Kesiapan keluarga dalam menerima klien tergambar dari jawaban responden yang mendapatkan total skor tertinggi adalah kesiapan aspek pemberian obat sedangkan yang terendah adalah kesiapan aspek lingkungan. Pertanyaan kesiapan keluarga dalam menerima klien yang mendapatkan skor tertinggi adalah pertanyaan nomor 5, ini menunjukkan bahwa seluruh keluarga sudah membuat jadwal minum obat klien gangguan jiwa sedangkan pertanyaan kesiapan keluarga 
Dinamika Kesehatan Jurnal Kebidanan dan Keperawatan Vol 10 No. 22019 ( ISSN: 2086-3454 EISSN: 2549-4058)

url: http://ojs.dinamikakesehatan.unism.ac.id DOI: https://doi.org/10.33859/dksm.v10i2

Hubungan Kesiapan Keluarga Menerima Klien Dengan Gangguan Jiwa Terhadap Angka Kekambuhan Pada Klien Gangguan Jiwa Di Poliklinik Rumah Sakit Jiwa Sambang Lihum Tahun 2018

dalam menerima klien yang mendapatkan

skor terendah adalah pertanyaan nomor 11 ,

ini menunjukkan bahwa keluarga sebagian

besar tidak melaksanakan kegiatan

keagamaan secara bersama-sama dengan

klien gangguan jiwa.

Keluarga pasien gangguan jiwa dalam penelitian ini sebagian besar dalam kategori siap menerima klien. Adapun penyebab hal tersebut adalah dari hasil pengolahan data jawaban keluarga klien gangguan jiwa yang sebelumnya sudah pernah dirawat inap, sehingga keluarga tersebut telah terpapar informasi mengenai cara perawatan klien gangguan jiwa.

Kesiapan keluarga dalam penelitian ini dapat berkaitan dengan karakteristik responden seperti umur. Persentase keluarga yang tidak siap lebih besar pada responden yang memiliki usia dewasa muda (<30 tahun). Hal ini dapat disebabkan karena seseorang yang masih muda cenderung untuk lebih tidak bisa merasakan atau mengenali kebutuhan orang lain termasuk anggota keluarganya dan juga bisanya lebih egois dibandingkan seseorang yang lebih tua sehingga yang lebih muda cenderug belum siap untuk merawat anggota keluarganya yang sakit. Usia berkaitan erat dengan tingkat kedewasaan. Usia yang semakin meningkat akan meningkatkan pula kemampuan seseorang dalam mengambil keputusan dalam hal ini kesiapan untuk merawat pasiengangguan jiwa. Seseorang yang bertambah usianya akan bertambah pula kedewasaannya dan semakin banyak menyerap informasi yang akan mempengaruhi kesiapan perawatan yang diberikan pada pasien gangguan jiwa. Hal ini sesuai dengan yang dikemukakan oleh Nuraenah (2012) semakin bertambah usia seseorang, maka semakin mampu menunjukkan kematangan jiwa, semakin bijaksana dalam mengambil keputusan, mampu berpikir rasional dan mampu mengendalikan emosi serta makin toleran terhadap orang lain.

Kesiapan keluarga dapat berkaitan dengan jenis kelamin responden. Persentase keluarga yang tidak siap dalam merawat 
Dinamika Kesehatan Jurnal Kebidanan dan Keperawatan Vol 10 No. 22019 ( ISSN: 2086-3454 EISSN: 2549-4058)

url: http://ojs.dinamikakesehatan.unism.ac.id DOI: https://doi.org/10.33859/dksm.v10i2

Hubungan Kesiapan Keluarga Menerima Klien Dengan Gangguan Jiwa Terhadap Angka Kekambuhan Pada Klien

Gangguan Jiwa Di Poliklinik Rumah Sakit Jiwa Sambang Lihum Tahun 2018

pasien gangguan jiwa sebagian besar adalah

laki-laki. Perempuan dan laki-laki biasanya

memiliki respon yang berbeda dalam

menghadapi masalah, laki-laki cenderung

tidak peduli, tidak memperhatikan

kesehatan dirinya sendiri maupun anggota

keluarganya, termasuk dalam merawat

pasien gangguan jiwa. Hal ini sesuai

dengan yang dikemukakan oleh Octavia

(2017) yang mengemukakan perempuan

dapat melakukan banyak hal dalam satu

waktu. Merawat keluarga, mengatur

keluarga serta mungkin bekerja, sehingga

kemungkinan adanya implikasi pada

ekonomi dan kemajuan perempuan di

berbagai bidang.

Bagi sebagian masyarakat, seseorang

yang mengalami gangguan jiwa merupakan

kondisi yang memalukan sehingga keluarga

pasien gangguan jiwa seringkali melakukan

pemasungan atau mengasingkan pasien.

Sementara itu, keluarga memiliki peran

utama dalam pemulihan kondisi pasien

gangguan jiwa pasca perawatan di rumah

sakit. Pelibatan keluarga dalam merawat pasien akan lebih efektif jika keluarga bisa

memahami kondisi pasien gangguan jiwa

dan menerimanya (Wardhani, 2015).

Keluarga merupakan tempat sosialisai pertama bagi penderita gangguan jiwa yang menjalani rawat inap saat penderita pulang ke rumah sebelum penderita kembali ke masyarakat. Kesiapan keluarga untuk menghadapi kembali penderita gangguan jiwa kembali ke rumah sangat penting. Namun kenyataannya beberapa keluarga pasien menunjukkan ketidaksiapan dalam menghadapi kepulangan pasien kembali ke rumah (Amalia, 2009).

Hasil penelitian ini sejalan dengan hasil penelitian Daulay (2016) yang menunjukkan bahwa penerimaan keluarga terhadap pasien skizofrenia di RS Jiwa Prof. Dr. M. Ildrem Medan sebagian besar termasuk dalam kategori baik sebanyak 24 orang $(58.5 \%)$,

2. Angka kekambuhan klien gangguan jiwa di Poliklinik Rumah Sakit Jiwa Sambang Lihum Provinsi Kalimantan Selatan 
Dinamika Kesehatan Jurnal Kebidanan dan Keperawatan Vol 10 No. 22019 ( ISSN: 2086-3454 EISSN: 2549-4058)

url: http://ojs.dinamikakesehatan.unism.ac.id DOI: https://doi.org/10.33859/dksm.v10i2

Hubungan Kesiapan Keluarga Menerima Klien Dengan Gangguan Jiwa Terhadap Angka Kekambuhan Pada Klien Gangguan Jiwa Di Poliklinik Rumah Sakit Jiwa Sambang Lihum Tahun 2018

Hasil penelitian didapatkan angka

kekambuhan klien gangguan jiwa sebagian

besar kategori sedang sebanyak 65 orang (67\%). Data tersebut menunjukkan bahwa klien gangguan jiwa sebagian besar mengalami kekambuhan >1 kali dalam setahun. Tingginya kekambuhan pada klien gangguan jiwa dapat disebabkan oleh faktor-faktor yang mempengaruhinya, salah satunya yaitu kesiapan keluarga dalam menerima klien gangguan jiwa di rumah.

Kekambuhan menunjukkan kembalinya gejala-gejala penyakit sebelumnya cukup parah dan menganggu aktivitas sehari-hari dan memerlukan perawatan inap dan rawat jalan yang tidak terjadwal. Kekambuhan gangguan jiwa adalah munculnya kembali simtom-simtom skizofrenik pada pasien yang sudah mengalami bebas gejala selama episode sebelumnya (Fitria, 2013).

Kambuh pada gangguan jiwa merupakan keadaan klien dimana muncul gejala yang sama seperti sebelumnya. Frekuensi kekambuhan adalah lamanya waktu tertentu atau masa dimana klien muncul lagi gejala yang sama seperti sebelumnya dan mengakibatkan klien harus dirawat kembali. Faktor-faktor yang mempengaruhi kekambuhan gangguan jiwa adalah klien, dokter tanggung jawab yang penting dalam proses perawatan di rumah sakit jiwa, persiapan pulang dan setelah penanggung jawab klien dan keluarga (Kelliat, 2011).

Hasil penelitian ini sama dengan hasil penelitian Purwantini (2015) yang mendapatkan bahwa sebagian besar pasien gangguan jiwa di RSJD Surakarta mengalami tingkat kekambuhan dengan kategori sedang sebanyak 28 orang $(50,9 \%)$

3. Hubungan kesiapan keluarga dalam menerima klien dengan angka kekambuhan klien gangguan jiwa di Poliklinik Rumah Sakit Jiwa Sambang Lihum Provinsi Kalimantan Selatan

Hasil penelitian didapatkan bahwa dari 77 orang keluarga yang siap menerima klien sebagian besar klien gangguan jiwa mengalami angka kekambuhan dengan 
Dinamika Kesehatan Jurnal Kebidanan dan Keperawatan Vol 10 No. 22019 ( ISSN: 2086-3454 EISSN: 2549-4058)

url: http://ojs.dinamikakesehatan.unism.ac.id DOI: https://doi.org/10.33859/dksm.v10i2

Hubungan Kesiapan Keluarga Menerima Klien Dengan Gangguan Jiwa Terhadap Angka Kekambuhan Pada Klien Gangguan Jiwa Di Poliklinik Rumah Sakit Jiwa Sambang Lihum Tahun 2018

kategori sedang sebanyak 65 orang $(84,4 \%)$

sedangkan dari 20 orang keluarga yang

tidak siap dalam menerima klien seluruh

klien gangguan jiwa mengalami angka

kekambuhan dengan kategori tinggi sebanyak $100 \%$.

Hasil analisis dengan menggunakan uji statistik menunjukkan bahwa ada hubungan kesiapan keluarga dalam menerima klien dengan angka kekambuhan pada klien gangguan jiwa di Poliklinik Rumah Sakit Jiwa Sambang Lihum Provinsi Kalimantan Selatan. Hasil penelitian ini menjelaskan bahwa semakin siap keluarga dalam menerima klien maka akan semakin mengurangi angka kekambuhan klien gangguan jiwa.

Keluarga yang melakukan berusaha untuk rutin membawa klien untuk mengontrol status kesehatannya maka akan semakin mengurangi angka kekambuhan klien. Keluarga yang berusaha memandirikan klien untuk bersosialisasi dan beraktifitas sehari-hari tentunya klien tersebut tidak hanya berdiam diri sehingga klien akan terhindar dari pikiran-pikiran yang mengganggu yang dapat berpotensi untuk kambuh kembali.

Keluarga yang selalu mengawasi klien terhadap gejala kekambuhan penyakit maka tentunya keluarga tersebut dapat mengatasi atau mencegah lebih dini terjadinya kekambuhan. Keluarga yang selalu mengawasi klien untuk minum obat tentunya pasien tersebut menjadi teratur kontrol dan mendapatkan obat yang diberikan sehingga pasien dapat mengkonsumsi obat tersebut untuk mencegah kekambuhan.

Bagi klien gangguan jiwa keluarga merupakan salah satu penyemangat hidup yang memberikan dorongan serta dukungan yang dibutuhkan salah satunya dengan selalu mengikutsertakan klien dalam kegiatan rumah, sehingga klien merasa lebih dihargai dan klien merasa nyaman dan terhindar dari kekambuhan.

Keluarga memiliki hubungan satu sama lain dalam suatu sistem keluarga terikat begitu ruwet sehingga suatu perubahan yang 
Dinamika Kesehatan Jurnal Kebidanan dan Keperawatan Vol 10 No. 22019 ( ISSN: 2086-3454 EISSN: 2549-4058)

url: http://ojs.dinamikakesehatan.unism.ac.id DOI: https://doi.org/10.33859/dksm.v10i2

Hubungan Kesiapan Keluarga Menerima Klien Dengan Gangguan Jiwa Terhadap Angka Kekambuhan Pada Klien

Gangguan Jiwa Di Poliklinik Rumah Sakit Jiwa Sambang Lihum Tahun 2018

terjadi pada satu bagian pasti menyebabkan

perubahan dalam seluruh sistem keluarga.

Setiap anggota keluarga dan subsistem akan

dipengaruhi oleh stressor transisional dan

situasional, tetap efek tersebut berbeda

intensitas ataupun kualitas. Oleh karena itu,

jika ada seorang anggota keluarga yang

mengalami masalah kesehatan baik fisik

maupun psikososial maka hal tersebut akan

dapat mempengaruhi kondisi keluarga

secara keseluruhan. Terapi keluarga dapat

mempercepat proses penyembuhan pasien

yang berdampak positif bagi dinamika

keluarga, menurunkan angka kekambuhan

dan keluarga menjadi mampu

meningkatkan pengertian terhadap pasien

sehingga lebih dapat menerima, lebih

bertoleransi dan lebih menghargai pasien

sebagai manusia dan dapat membantu

pasien dalam proses rehabilitasi (Yusuf.,

dkk, 2015).

Keluarga klien perlu mempunyai sikap

yang positif untuk mencegah kekambuhan

pada klien gangguan jiwa. Keluarga perlu

memberikan dukungan (support) kepada klien untuk meningkatkan motivasi dan tanggung jawab untuk melaksanakan perawatan secara mandiri. Keluarga perlu mempunyai sikap menerima klien, memberikan respon positif kepada klien, menghargai klien sebagai anggota keluarga dan menumbuhkan sikap tanggung jawab pada klien. Sikap permusuhan yang ditunjukkan oleh anggota keluarga terhadap klien akan berpengaruh terhadap kekambuhan klien. Tindakan kasar, bentakan, atau mengucilkan malah akan membuat penderita semakin depresi bahkan cenderung bersikap kasar. Akan tetapi terlalu memanjakan juga tidak baik (Arisandy, 2015).

Hasil penelitian ini sejalan dengan penelitian Pratama (2015) yang menyatakan bahwa adanya hubungan keluarga dengan kekambuhan skizofrenia di Badan Layanan Umum Daerah (BLUD) Rumah Sakit Jiwa Aceh $(\mathrm{p}$ value $=0,000)$. 
Dinamika Kesehatan Jurnal Kebidanan dan Keperawatan Vol 10 No. 22019 ( ISSN: 2086-3454 EISSN: 2549-4058)

url: http://ojs.dinamikakesehatan.unism.ac.id DOI: https://doi.org/10.33859/dksm.v10i2

Hubungan Kesiapan Keluarga Menerima Klien Dengan Gangguan Jiwa Terhadap Angka Kekambuhan Pada Klien

Gangguan Jiwa Di Poliklinik Rumah Sakit Jiwa Sambang Lihum Tahun 2018

\section{Simpulan}

Kesimpulan penelitian ini adalah sebagai berikut:

1. Kesiapan Keluarga klien gangguan jiwa di Poliklinik Rumah Sakit Jiwa Sambang Lihum Provinsi Kalimantan Selatan sebagian besar siap dalam menerima klien gangguan jiwa yaitu sebanyak 77 orang $(79,4 \%)$

2. Angka kekambuhan klien gangguan jiwa di Poliklinik Rumah Sakit Jiwa Sambang Lihum Provinsi Kalimantan Selatan sebagian besar kategori sedang sebanyak 65 orang $(67 \%)$.

3. Ada hubungan kesiapan keluarga dalam menerima klien dengan angka kekambuhan pada klien gangguan jiwa di Poliklinik Rumah Sakit Jiwa Sambang Lihum Provinsi Kalimantan Selatan $(\mathrm{p}$ value $=$ $0,000 ; r=0,744)$.

\section{Saran}

Saran yang dapat diberikan dalam penelitian ini adalah sebagai berikut:

1. Bagi STIKES Cahaya Bangsa
Hendaknya Instansi Pendidikan dapat

memberikan program kepada mahasiswa keperawatan untuk melakukan promosi kesehatan pada saat Praktek Kerja Lapangan (PKL) dengan cara lebih meningkatkan satuan penyuluhan keluarga atau membagikan selebaran mengenai kesiapan dalam menerima klien gangguan jiwa.

2. Bagi Rumah Sakit Jiwa Sambang Lihum

Diharapkan dapat memberikan sosialisasi misalnya melalui kegiatan peningkatan penyuluhan kepada keluarga klien gangguan jiwa melalui pembagian leaflet, brosur ataupun selebaran, serta rumah sakit dapat melakukan home visite kepada keluarga pasien untuk meningkatkan pelayanan asuhan keperawatan pada klien gangguan jiwa dan keluarga.

3. Bagi peneliti selanjutnya

Perlunya penelitian lebih lanjut mengenai kesiapan dalam menerima klien gangguan jiwa dengan variabel lainnya yang juga diduga turut serta mempengaruhi misalnya lama sakit. 
Dinamika Kesehatan Jurnal Kebidanan dan Keperawatan Vol 10 No. 22019 ( ISSN: 2086-3454 EISSN: 2549-4058)

url: http://ojs.dinamikakesehatan.unism.ac.id DOI: https://doi.org/10.33859/dksm.v10i2

Hubungan Kesiapan Keluarga Menerima Klien Dengan Gangguan Jiwa Terhadap Angka Kekambuhan Pada Klien Gangguan Jiwa Di Poliklinik Rumah Sakit Jiwa Sambang Lihum Tahun 2018

\section{Daftar Pustaka}

Amalia, L. 2009. Kesiapan Keluarga Menghadapi Kepulangan Pasien Rawat Inap Gangguan Jiwa Studi Kasus pada Keluarga Pasien Rawat Inap Ganguan Jiwa di Rumah Sakit Jiwa dr. Amino Gondhohutomo Semarang [Online]. tersedia dalam http://lib.unnes.ac.id/3800/1/5734.pdf [diakses tanggal 18 Agustus 2018].

Daulay, H. R. 2016. Hubungan Penerimaan Keluarga dengan Kemampuan Merawat Pasien Skizofrenia di RS Jiwa Prof. Dr. M. Ildrem Medan [Online]. tersedia dalam http://repositori.usu.ac.id [diakses tanggal 18 Agustus 2018].

Fitria, M. S. 2013. Hubungan antara Faktor Kepatuhan Mengkonsumsi Obat, Dukungan Keluarga dan Lingkungan Masyarakat dengan Tingkat Kekambuhan Pasien Skizofrenia di RSJD Surakarta [Online]. tersedia dalam http://eprints.ums.ac.id/27203/17/NAS

KAH_PUBLIKASI.pdf [diakses tanggal 18 Agustus 2018].

Kelliat, B. A. 2011. Manajemen Kasus Gangguan Jiwa CMHN (Intermediate Course). Jakarta : EGC.

Nuraenah. 2012. Hubungan Dukungan Keluarga dan Beban Keluarga dalam Merawat Anggota dengan Perilaku Kekerasan di RS. Jiwa Islam Klender Jakarta Timur [Online]. tersedia dalam http://digillib.ui.ac.id [diakses tanggal 18 Agustus 2018].

Purwantini. 2015. Hubungan Tipe Keperibadian dengan Kekambuhan Gangguan Jiwa di Rumah Sakit Jiwa Daerah Surakarta [Online]. tersedia dalam,http://digilib.stikeskusumahusada .ac.id [diakses tanggal 18 Agustus 2018].
Pratama, Y. 2015. Hubungan Keluarga Pasien terhadap Kekambuhan Skizofrenia di Badan Layanan Umum Daerah (BLUD) Rumah Sakit Jiwa Aceh [Online]. tersedia dalam http://www.jurnal.unsyiah.ac.id/JKS/arti cle/view/3258/3082 [diakses tanggal 18 Agustus 2018].

Octavia, S. I. 2017. Peranan Penting Wanita dalam Menjaga Kesehatan Keluarga [Online]. tersedia dalam http://corporate.kimiafarmaapotek.co.id [diakses tanggal 18 Agustus 2018].

Wardhani, R. Z. 2015. Penerimaan Keluarga Pasien Skizofrenia yang Menjalani Rawat Inap di RSJ [Online]. tersedia dalam https://publikasiilmiah.ums.ac.id [diakses tanggal 18 Agustus 2018].

Yusuf, A., Fitryasari, R., Nihayati, H. E. 2015. Buku Ajar Keperawatan Kesehatan Jiwa. Jakarta: Salemba Medika

http://m.harnas.co/2017/06/15/Penderitagangguan-jiwa-di-kalsel-capai-6000 orang tanggal di akses 24 maret 2018. 